\title{
Analytical Design for Stable Channel Geometry of Naesung Stream in Korea
}

\author{
U. Ji
}

Korea Institute of Civil Engineering and Building Technology/Korea University of Science and Technology

E.K. Jang

Korea Institute of Civil Engineering and Building Technology

\begin{abstract}
A stable channel is one in which channel dimensions of slope, width, and depth remain balanced with equilibrium condition between input and output sediment discharge and erosion and sedimentation of channel beds and banks. In the analytical method of stable channel design, stable channel slopes and depths with given channel widths are determined by satisfying the condition that the upstream incoming sediment rate is equal to the sediment transport rate at the design channel. Therefore, the most sensitive parameter when designing a stable channel is the choice of a sediment transport equation applied for the channel design. The Stable Channel Analysis and Design (SCAD) program has been developed for the better option of various sediment transport equations and for calculation of a unique solution considering design constraints such as fixed width and depth as well as various solutions for stable channel condition with a wide range. The study reach of Naesung Stream in Korea has been selected for this study. The Naesung Stream is a tributary of Nakdong River and mostly sand bed. The stable channel analysis and design for the study section has been performed using the SCAD program with different sediment transport equations for sensitivity analysis and design constraints.
\end{abstract}

\section{INTRODUCTION}

River restoration and maintenance projects for alluvial channels with movable beds and banks require equilibrium geometries to minimize channel deformation by erosion and sedimentation. Stable channel design for cross-sectional geometry and slope of alluvial channels is a key to reducing the cost of river maintenance and management after projects. A stable channel is one in which channel dimensions of slope, width, and depth remain balanced between erosion and sedimentation of channel beds and banks, input and output sediment discharge (Griffiths, 1983). To solve the three components of width, depth, and slope, three independent equations are required. Design width may be determined using the analytical method and hydraulic geometry equation (Garcâia, 2008). The three components of width, depth, and slope, channel width could sometimes be constrained by limitations and design width could be fixed for stable channel design. Depth and slope should be determined using analytical techniques which are based on physical laws and limited empiricism. The engineer could select any appropriate flow resistance and sediment transport relations for two equations to provide a unique solution for three dependent variables. Using the width from a hydraulic geometry predictor, from a reference reach, or from a given constrainer, a unique slope and depth are determined. Copeland's method (1994) is commonly used for stable channel design and is implemented. However, despite the most sensitive variable when designing, the sediment transport capacity for the design channel is calculated by restrictive equation (Jang et al., 2015). Therefore, the stable channel analysis which can apply various sediment transport equations is required to design. The objectives of this study are to calculate of stable channel for three different streams using the SCAD (Stable Channel analysis \& Design) developed for apply various sediment transport equations and to compare the dimensions of stable channels by Korea Institute of Civil Engineering and Building Technology (KICT). The study reaches has been selected Naesung stream in Korea. The Naesung Stream is sand bed channel. The results produced by this study would be used as a basis for developing the evaluating procedure to determine the stable channel geometry. 
A stable channel is one in which channel dimensions of slope, width, and depth remain balanced with equilibrium condition between input and output sediment discharge and erosion and sedimentation of channel beds and banks (Fig. 1). In the analytical method of stable channel design, stable channel slopes and depths with given channel widths are determined by satisfying the condition that the upstream incoming sediment rate is equal to the sediment transport rate at the design channel. Therefore, the most sensitive parameter when designing a stable channel is the choice of a sediment transport equation applied for the channel design. Methods for calculating a stable channel section have been proposed by a number of researchers. Of the various analytical methods, Copeland's method (1994) is the most widely used method of stable channel evaluation and design for alluvial channels. This method is similar to Abou-Seida and Saleh's method (1987). Of the three unknown values, two unknown values are first calculated. Then an engineer (or designer) selects a solution with the third value, which is the most appropriate for design and geometry constraints. Unlike other methods, the SCAD provides a number of final solutions rather than a single solution, and it also gives a solution with the minimum stream power. Copeland's method (1994) is an analytical method based on an empirical equation for stable width. The Stable Channel Analysis and Design (SCAD) program has been developed for the better option of various sediment transport equations and for calculation of a unique solution considering design constraints such as fixed width and depth as well as various solutions for stable channel condition with a wide range. Stable depth and slope for the channel base width, determined by the empirical equation, are calculated using the sediment transport equation and flow depth prediction of Brownlie (1981). In this study, more equations are adopted to calculate sediment capacity during stable channel design, and stable channel calculation can be performed by additionally selecting Ackers and White (1973)'s, Engelund and Hansen (1967)'s, Yang (1979)'s and Meyer-Peter and müller (1948)'s equations (Jang et al., 2015).

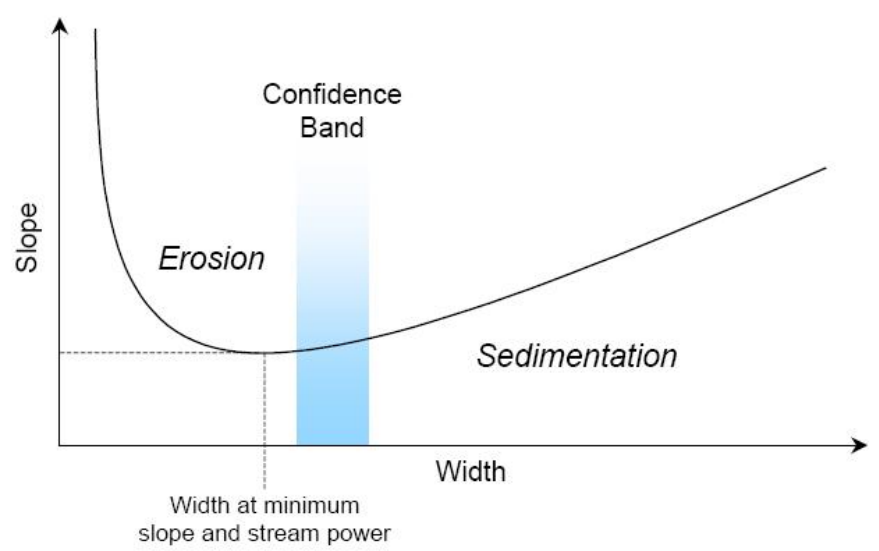

Figure 1. Analytic Channel Design for Stable Depth and Slope (Soar and Thorne, 2001)

\section{DEVELOPENT ALGORITHMS FOR SCAD PROGRAM}

Copeland's method (1994) is the most widely used method of stable channel design. Critically, Copeland's method (1994) for stable channel design is limited because only Brownlie (1981)'s equation can be applied for calculating sediment capacity $\left(C^{\prime}\right)$, whereas the SCAD program developed so that various sediment transport equations can be applied. Both Copeland's method (1994) and the program developed in this study determine stable width using an empirical formula, and then the solutions for stable depth and slope are derived using a trial and error method. The process of calculation for stable channel section can be broadly divided into channel geometry calculation, flow regime analysis, and sediment capacity calculation (Fig. 2). First, when the three unknown values are not yet determined, the design width is calculated using a regime equation of $\mathrm{W}=2.0 \sqrt{\mathrm{Q}_{\mathrm{c}}}$ suggested by USACE (1994). The stable depth and width are calculated by inputting a channel-forming discharge $\left(Q_{c}\right)$, a specific gravity of sediment $(G)$, a particle size distribution of bed materials $\left(\mathrm{d}_{84}, \mathrm{~d}_{50}\right.$, and $\left.\mathrm{d}_{16}\right)$, a valley slope $\left(\mathrm{S}_{\mathrm{v}}\right)$, and a bank slope $\left(\mathrm{S}_{\mathrm{S}}\right)$, with the assumptions that the arbitrary initial depth $\left(D_{0}\right)$ is $1 / 2$ of the stable width and that the valley slope is equal to the initial stable slope. When the channel section is determined, the upper regime and lower regime for channel-forming discharge or bankfull discharge can be judged. For the determined flow regime, the roughness coefficient $(\mathrm{n})$ is calculated, and then the sediment capacity $\left(\mathrm{C}^{\prime}\right)$ is calculated by selecting a sediment transport equation, which is appropriate for a target river, from among Ackers and White (1973)'s, Brownlie (1981)'s, Engelund and Hansen (1967)'s, and Yang (1979)'s equations. Figure 1 shows the algorithm for the overall calculation. The calculation is performed until the sediment capacity $\left(\mathrm{C}^{\prime}\right)$, which has been cal- 
culated through the above process, equals the incoming sediment from the upstream reach $(\mathrm{C})$, by reassuming depth and slope, and then final solutions are derived. The overall calculation process provides a total of 21 solutions by varying the width by $\pm 10 \%$ from the regime width.

In addition, there may be geographical constraints on the determination of channel width or depth during the practical performance of a river restoration project. Therefore, when the width (W) cannot be considered as a design parameter, the channel width is input as a fixed value. The calculation of stable depth and slope is repeated until the incoming sediment from the upstream channel is equal to the sediment capacity of the stable channel section. In contrast, when the depth (D) needs to be fixed, the stable width (W) and slope are determined. Three algorithms are applied to develop the SCAD program (Jang et al., 2015).

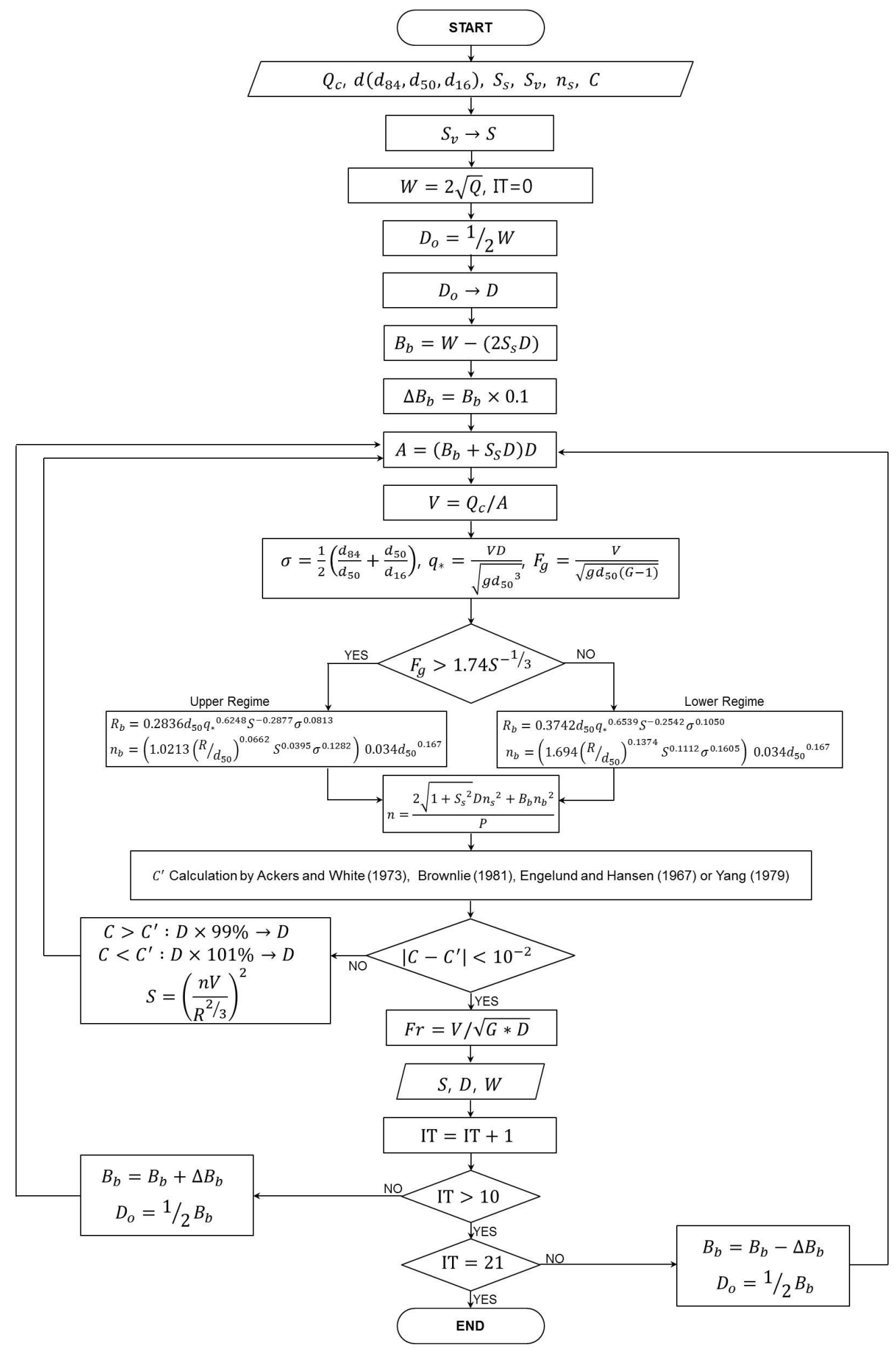

Figure 2. Algorithm for Stable Channel Design Calculation (Jang et al., 2015) 


\section{APPLICATION FOR STABLE CHANNEL DESIGN IN THE NAESUNG STREAM}

\subsection{Study reach of the Naesung stream}

The Naesung Stream is a tributary of Nakdong River in South Korea. The basin area based on Naesung Station is $1,814.7 \mathrm{~km}^{2}$, and the annual mean precipitation is $1,245 \mathrm{~mm}$. The bankfull discharge of the study reach was determined using the HEC-RAS (Hydrologic Engineering Center River Analysis System) simulation data, and it was used as the reference discharge for stable channel calculation (i.e., channel-forming discharge).

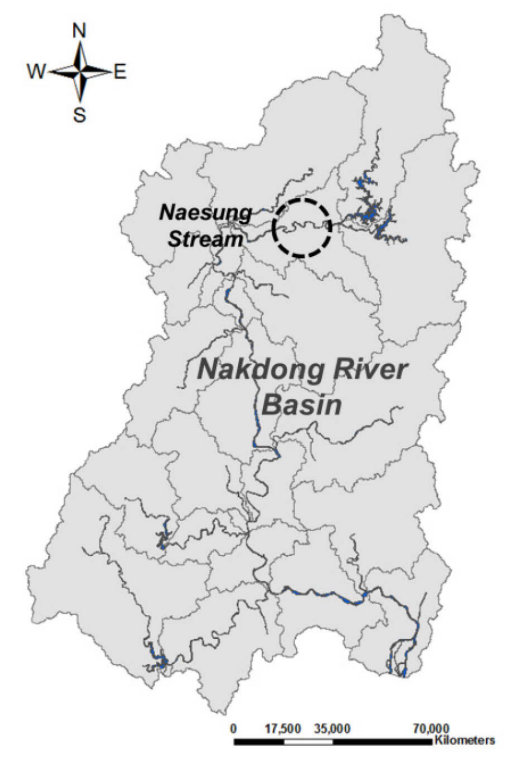

Figure 3. Study Reach of Naesung Stream

\subsection{Calculation conditions for SCAD}

The bed slope for stable channel analysis and design of the study reach was 0.00145 . The roughness coefficient of the target section was calculated as 0.06 through the water surface level verification based on the observed stage and backwater calculation, and the roughness coefficient of the bank was also assumed to be 0.06 . The particle size distribution data of bed materials observed by KICT (2014) was used. The bed materials of the target section were the median particle size was $5.85 \mathrm{~mm}$. The side slope of the bank in the upstream channel where sediment is supplied was $498 \mathrm{ppm}$ and the side slope of the bank for the stable channel design section was also set to 0.303 .

In this study, to provide more options for engineers and researchers to use Copeland's method, SCAD additional selected sediment transport equations for sand and gravel bed channels have been developed. The users can select one to several sediment transport equations by considering the applicability of the sediment transport equation before using the program. The applicability of Ackers and White (1973)'s, Engelund and Hansen (1967)'s, Yang (1979)'s, Brownlie (1981)'s and Meyer-Peter and müller (1948)'s sediment transport equations for the study reach of Naesung Stream was confirmed and five equations were applied to perform the sensitivity analysis.

\section{STABLE CHANNEL ANALYSIS IN THE NAESUNG STREAM}

The SCAD program developed by KICT was used to analyze the current geometric condition at the Naesung Stream. Fiver different sediment transport equations are applied in the program to calculate the stable channel section with width, depth, and slope. Also, the stable channel results calculated using various sediment transport equations were compared with the current section of the Naesung Stream, as shown in Figure 4 and Figure 5. The Ackers and White (1973)' equation was except to compare because it calculated abnormal result.

The analysis results indicated that Brownlie (1981)'s equation, the predicted slope was steeper than the slope of the current section (0.00145) and the slope predicted using Yang (1979)'s equation was the mildest at the same base width and slope. According to Engelund and Hansen (1967)'s and Meyer-Peter and müller (1948)'s equations, the current section is stable slope and base width (Fig. 4).

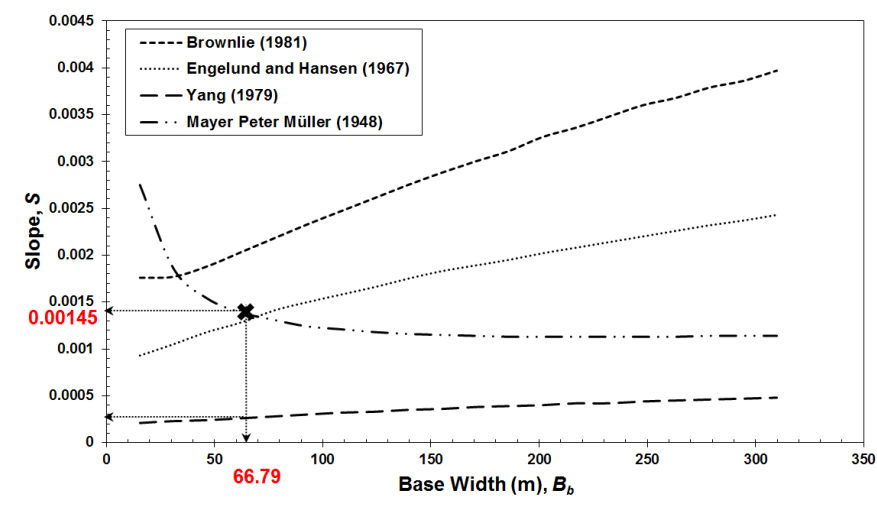

Figure 4. Relation between stable slope and base width comparison of Stable Channel Design with Currents Section

The analyzed stable slope and depth relation results of the Naesung Stream using various sediment transport equations indicated that the current section had deeper depth and milder bed slope compared to the stable channel prediction results. The analysis results indicated that Brownlie (1981)'s and Engelund and Hansen (1967)'s equations, the predicted slope was steeper than the slope of the current section (0.00145) and the slope predicted using Yang (1979)'s and Meyer-Peter and müller (1948)'s equations were the mildest at the same base width and slope. 


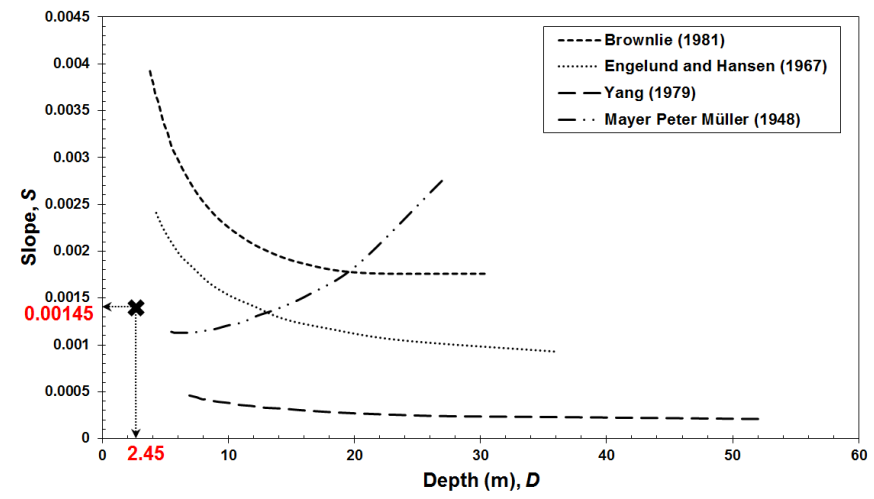

Figure 2. Relation between stable slope and depth comparison of Stable Channel Design with Currents Section

\section{CONCLUSION}

The study results of relation between stable slope and base width indicated that current section is stable slope and base width by Engelund and Hansen (1967)'s and Meyer-Peter and Müller (1948)'s equations. In case of relation between stable slope and depth, Brownlie (1981)'s and Engelund and Hansen (1967)'s equations indicated that the current section has shallower depth and Yang (1979)'s and MeyerPeter and Müller (1948)'s equations indicated that the current section has deeper depth compared to the stable channel prediction by SCAD program. It could be represented in relation to the formation of sandbar around the current section in the Naesung Stream.

Stable channel geometries of width, depth, and slope predicted for three case studies in Korea had a wide range of results by different sediment transport equations. It is concluded that the uncertainty and sensitivity of stable channel design depending on sediment transport equations should be examined and considered for practical implementation.

\section{ACKNOWLEDGEMENT}

This research was supported by a grant (12-TI-C02) from Advanced Water Management Research Program funded by Ministry of Land, Infrastructure and Transport of Korean government.

\section{REFERENCE}

Abou-Seida, M. M. \& Saleh, M. 1987. Design of stable alluvial channels, Journal of hydraulic research, 25( 4): 433-446.

Ackers, P. \& White, W. R. 1973. Sediment transport: A new approach and analysis, Journal of hydraulics division, ASCE, 99(11): 2041-2060.

Brownlie, W.R. 1981. Prediction of flow depth and sediment transport in open channels, Report No. KH-R-43A, Institute of Technology, California.

Copeland, R.R. 1994. Application of channel stability methods - Case studies, Technical report No. HL-94-11, united states army corps of engineers, Waterways experiment station, Vicksburg, Mississippi.

Engelund, F. \& Hansen, E.E. 1967. A monograph of sediment transport in alluvial rivers, technical university of Denmark, Copenhagen, pp. 62.

Garcia, M.H. 2008. Sedimentation engineering: processes, measurements, modeling, and practice, ASCE Publications, World environmental and water resource congress, 1-4.

Griffiths, G.A. 1983. Stable-channel design in alluvial rivers, Journal of hydrology, 65(4): 259-270.

Jang, E.K., Ji, U, Kim, K.H. \& Yeo, W.K. 2015. Stable channel design with different sediment transport equations and geomorphologic constraints in Cheongmi Stream, KSCE journal of civil engineering, published online September 11, 2015.

KICT. 2014. Analysis of change in river morphology and vegetation due to artificial structures, internal research project, Korea institute of civil engineering and building technology, KICT 2014-244.

Meyer E. Peter \& Müeller, R. 1948. Formulas for bed-load transport, Proceedings of the 2nd meeting of the international association for hydraulic, International association of hydraulic research Delft, Sweden, :9-64.

USACE. 1994. Engineering and design: channel stability assessment for flood control channels, Engineering manual 1110-2-1418, CECW-EHD, United states department of the army, Washington, D.C.

Yang, C.T. 1979. Unit stream power equation for total load, Journal of hydrology, 40: 123-138. 